\title{
Human Immunodeficiency Virus is a Driven Factor of Human Papilloma Virus among Women: Evidence from a Cross-sectional Analysis in Yaoundé, Cameroon
}

Samuel Martin SOSSO ( $\sim$ martinsosso@yahoo.it)

Michel Carlos Tommo Tchouaket

CIRCB; School of Health Sciences, Catholic University of Central Africa, Yaoundé Joseph Fokam

CIRCB; School of Health Sciences, Catholic University of Central Africa, Yaounde; University of Yaounde

I, Cameroon

Rachel Kamgaing Simo

CIRCB

Judith Torimiro

CIRCB; University of Yaounde I, Cameroon

Aline Tiga

CIRCB

Elise Elong Lobe

CIRCB

Georgia Ambada

CIRCB; University of Yaounde I, Cameroon

Achille Nange

CIRCB

Ezechiel Ngoufack Jagni Semengue

CIRCB; University of Rome Tor Vergata, Italy

Alex Durand Nka

CIRCB; Universita degli Studi di Roma Tor Vergata, Italy

Valère Tala

CIRCB; University of Yaounde I, Cameroon

Collins Chenwi

CIRCB; University of Yaounde I, Cameroon

Aissatou Abba

CIRCB; School of Health Sciences, Catholic University of Central Africa, Yaounde

Aude Christelle Ka'e

CIRCB; University of Yaounde I, Cameroon 


\section{Bouba Yagai}

CIRCB; University of Rome, Tor Vergata, Italy

\section{Vittorio Colizzi}

Universita degli Studi di Roma Tor Vergata Dipartimento di Medicina Sperimentale e Chirurgia

\section{Alexis Ndjolo}

CIRCB; University of Yaounde I, Cameroon

\section{Research}

Keywords: HPV, HIV, Women, Yaoundé

Posted Date: January 8th, 2020

DOI: https://doi.org/10.21203/rs.2.20286/v1

License: (c) (1) This work is licensed under a Creative Commons Attribution 4.0 International License.

Read Full License

Version of Record: A version of this preprint was published at Virology Journal on May 19th, 2020. See the published version at https://doi.org/10.1186/s12985-020-01340-y. 


\section{Abstract}

Background: Human papillomavirus (HPV) is the leading cause of cervical cancers, causing 270.000 deaths annually worldwide of which $85 \%$ occur in developing countries with an increasing risk associated to HIV infection. This study aimed at comparing HPV's positivity and genotype distribution in women according to their HIV status and determinants.

Methods: A comparative study was carried out in 2012 at the Chantal BIYA International Reference Centre (CIRCB) among 278 women enrolled consecutively at the General Hospital and the Gynaeco-Obstetric and Paediatric Hospital of the City of Yaoundé. HPV genotyping was performed by real-time PCR, HIV serological screening by serial algorithm, CD 4 T cell phenotyping by flow cytometry and HIV viral load by Abbott m2000RT. Statistical analyses were performed using Microsoft Excel 2016 and Graph Pad version 6.0 software; with $\mathrm{P}<0.05$ considered statistically significant.

Results: Globally, mean age was $37 \pm 3$ years; median CD4-count for HIV+ was 414 cells/mm 3 [IQR: 264.75-588] and median viremia was 50 RNA copies/mL [IQR: $<40-8288$ ]. Overall HPV rate was $38.49 \%$ (107/278); $58.88 \%$ for single women vs. others (28.97\% married, $2.80 \%$ divorced, $9.34 \%$ for widows), OR: 2.164; $p=0.0319$. Following HIV status, HPV rate was $43.48 \%$ (80/184) among HIV+ vs. $28.72 \%(27 / 94)$ among HIV-(OR: 1.937; $p<0.0142)$; HPV genotypes among HIV+ vs. HIV- were respectively distributed as follows: genotype 16 (3.75\% vs. $0.00 \%, p=0.57)$, genotype 18 (3.75\% vs. 3.70\%, $p=1.00)$, co-infection 16 and others ( $8.75 \%$ vs. $7.40 \%, p=1.00)$, co-infection 18 and others ( $8.75 \%$ vs. $11.11 \%, p=0.71)$, co-infection 16,18 and others $(2.50 \%$ vs. $0.00 \%, p=1.00)$ and other genotypes $(72.50 \%$ vs. $77.78 \%, p=0.80)$. Among HIV+ participants, HPV rate following CD4 was $62.88 \%$ (61/97) for CD $4<500$ vs. $35.71 \%(20 / 56)$ for CD4 $\geq 500$ (OR: 3.05; $p=0.0012$ ) while HPV rate following HIV viremia was $42.71 \%$ (41/96) with <1000 RNA copies/ml vs. $66.00 \%$ (33/50) with $>1000$ RNA copies/ml (OR=0.384; $p=0.009)$.

Conclusion: In Yaoundé, HPV rate appear to be very high, with higher rates of genotypes other than 16 and 18. In the event of HIV infection, the risk of HPV positivity is two times higher, favoured essentially by immunodeficiency. Thus, HIV-infected women should be closely monitored to prevent the emergence of cervical cancer.

Keywords: HPV, HIV, Women, Yaoundé

\section{Background}

Human papilloma viruses (HPV) are non-enveloped DNA viruses that represent the most widespread sexually transmitted infection worldwide, with more than 200 species. HPV genotypes are responsible for $95 \%$ of the occurrence of cervical cancer in women [1]. Notably, HPV causes benign and malignant tumours in humans and viral genotypes that are oncogenic are classified as high-risk (HR-HPV) or lowrisk oncogenic HPV (LR-HPV) [2]. Although all HR-HPV genotypes have oncogenic potential, some are more frequently involved in cancers than others. Thus, HPV 16 and 18 represent approximately $70 \%$ of all 
cervical cancers worldwide, followed by HPV 31, 33, 45, 52, 58 and 68 which are among the ten most commonly isolated HR-HPV genotypes from cervical tumor biopsies [3, 4].

Indeed, cervical cancer is known to be a viro-induced neoplasm and that HPV is the causal agent in $99 \%$ of cases [4]. According to the World Health Organization (WHO), cervical cancer will kill more than 443 000 people worldwide each year by 2030 , and $98 \%$ of these deaths will occur in developing countries, particularly in sub-Saharan Africa (SSA) where the HIV epidemic and other risk factors further increase the burden of this cancer $[5,6]$. In SSA, HPV and HIV co-infection is commonly found and contributes to a rapid disease progression toward cervical cancer [4]. Importantly, HIV-positive women, especially those who are severely immunocompromised, are 5 times more likely to develop the cervical cancer than their HIV-negative peers.

Even though little is known on HPV genotypes circulating among HIV-infected women in SSA countries, recommendations for HPV vaccination in the population of people living with HIV (PLHIV) are still unclear [7]. Of note, people exposed to HPV are able to eliminate the virus and the viral clearance can last from 12 to 18 months. For $10 \%$ of HPV-infected individuals, there is viral persistence that remains at latency. In this frame, immunodeficiency may be the cause of viral persistance and reactivation subsequently $[7,8]$.

Factors that contribute to HPV infections include: early sexual activity, multiple sexual partners, immunocompromised (HIV essentially), smoking, and prolonged oral contraception [8]. Thus, the primary prevention of cervical cancer by vaccinating girls aged 9 to 14 years with one of the 3 available vaccines (Cervarix, Gardasil-4 or Gardasil-9) before they begin sexual intercourse would theoretically protect them against most HR-HPV infections $[9,10]$. This primary prevention, combined with other prevention strategies (secondary and tertiary prevention) already in place in SSA, would be the ideal equation to overcome the high burden of cervical cancer on this continent $[11,12]$.

A recent study conducted in Chad during the year 2018 showed that the HPV types targeted by the Gardasil-9 prophylactic vaccine were detected in nearly $70 \%$ of the study population, and HR-HPV 58 genotype was the most common in the population (22.9\%) [10]. In Cameroon, out of 14,000 new cases of cancer reported in 2016, among which cervical cancer occupied the second leading position of cancers among women $(23.2 \%)[10,13]$. These observations are very concerning and suggest a high burden of HPV in these settings where HIV is also highly prevalent [14-16]. Thus, in the light of evidence generated from countries with similar programmatic challenges [17, 18], understanding the burden of HPV among women, its circulating genotypes and the effect of HIV-infection on HPV-positivity within the Cameroonian context, might help in shaping HPV preventive measures according to local realities.

Our study objective was to compare the rate of HPV-positivity according to HIV-serostatus, and to determine other predictors of HPV-positivity.

\section{Methods}

\section{Study design and setting}


A cross-sectional study was carried-out in 2012 from women attending the General Hospital and the Gyneco-obstetrical Hospital, both located in Yaoundé, the capital city of Cameroon. For all enrolled women, blood and cervical samples were collected. HIV screening tests, CD4 lymphocyte counts, HIV viral load, and HPV genotyping were performed at the Chantal BIYA International Reference Centre for research on HIV/AIDS prevention and management (CIRCB) in Yaoundé, Cameroon

(http://circb.cm/btc_circb/web/). Briefly, CIRCB is a reference centre for HIV/AIDS, performing laboratory analysis with external quality controls and proficiency testing for HIV screening (CDC DTS), HIV early infant diagnosis (CDC PT program), CD4 and viral load (QASI, Canada).

\section{Sampling strategy}

Following a consecutive non-probabilistic sampling method, a minimum sample size of 272 was required to meet the study outcomes. Consenting women, sexually active, aged 18 years and above, were eligible for the study. However, women who had undergone a total hysterectomy were not considered for inclusion. After consenting, a standard questionnaire was administered to all participants, covering sociodemographic characteristics, gynaeco-obstetrical and reproductive history. Whole blood and cervical samples were collected; cervico-vaginal smear reading was done; HIV screening was performed following a serial algorithm as per the national guidelines, plasma HIV-1 viral load (solely for HIV + cases) was done using the Abbott m2000 RT-PCR platform, enumeration of CD4 T lymphocyte was performed by using the FACS Calibur of Becton Dickinson.

\section{HPV genotyping}

For HPV genotyping, the Abbott Real Time HR-HPV test was used. Briefly, viral DNA was extracted and amplified using the Abbott real-time polymerase chain reaction assay, with simultaneous detection and genotyping of HPV 16, HPV 18, and a pooled detection of 12 other HR-HPV genotypes (HPV 31, HPV 33, HPV 35, HPV 39, HPV 45, HPV 51, HPV 52, HPV 56, HPV 58, HPV 59, HPV 66 and HPV 68).

\section{Statistical analysis}

Data were collected using Excel 2016, and analyses were performed using Epi-info version 7 and Graph pad prism version 6 . Odd ratio (OR) was calculated to determine whether the variable was a risk or protective factor. The confidence interval $(\mathrm{Cl})$ for the statistical tests was set at $95 \%$, and the null hypothesis rejected at a $5 \%$ threshold. P-values $\leq 0.2$, obtained in uni- or bi-variate analysis, were considered in the multivariate analysis.

\section{Ethics considerations}

Ethical clearance was obtained from the CIRCB Ethics Committee (ref $\mathrm{N}^{0} 1810$ ), and administrative authorization was provided by the facilities where the study was conducted. Written informed consent was provided by each participant, and results were delivered free of charge to participants for their clinical benefits.

\section{Results}




\section{Sociodemographic and bioclinical characteristics of the study population}

A total of 278 eligible women were enrolled as participants in this study, giving an enrollment rate of $103 \%$ (278/272) according to the required minimum sample size. According to HIV sero-status, 184 women were HIV-seropositive and 94 were HIV-seronegative. The mean age was 37 years \pm 3 years, similar between HIV-seropositive women (36.7 years) as comapred to HIV-seronegative women (37.3 years). The most represented age range was [30-39] years (44\%). Single women were the most represented (58.88\%), followed by married women (28.97\%), widows (9.34\%), and divorced $(2.80 \%)$.

\section{Immune status of HIV+/HIV- patients}

Women with a normal immunity (CD4 $\geq 500)$ were fewer $(35.71 \%)$ as compared to those immunocompromised $(C D 4<500)$ representing $62.88 \%$ of the general population. The overall median [IQR] CD4 count was 399 cells $/ \mathrm{mm}^{3}$. According to HIV-serostatus, median CD4 was lower (354 [231-530 cells] cells $/ \mathrm{mm}^{3}$ ) among HIV-seropositive women as compared to their sero-negative peers (414 [IQ 262918 cells $\left./ \mathrm{mm}^{3}\right]$ ).

\section{HPV positivity rate and circulating genotypes}

Overall, HPV positivity rate was $38.49 \%$ (107/278), indicating a high burden of HPV in the study population (Table 1). According to HIV sero-status, HPV prevalence was significantly higher in the group of HIV-seropositive women ( $43.47 \%$ vs. $28.42 \%, p=0.019)$, indicating that HIV-infection increasing by about 8 folds more risks of acquiring HPV as compared to those free of HIV (OR: 8.609, 95\% Cl: 2.841$27,338)$.

Table 1

HPV positivity according to HIV serostatus

\begin{tabular}{|lllll|}
\hline $\begin{array}{l}\text { HPV } \\
\text { HIV }\end{array}$ & HPV + & HPV - & Total & P-value \\
\hline HIV+ & $80(43.47 \%)$ & 104 & 184 & \\
\hline HIV- & $27(28.42 \%)$ & 67 & 95 & 0.019 \\
\hline Total & $107(38.48 \%)$ & 171 & 278 & \\
\hline
\end{tabular}

\section{Diversity of HPV genotypes in infected women}

Several HPV genotypes were identified in the study population. interestingly, $74 \%$ of women were infected by non-discriminated high-risk genotypes $(31,33,35,39,45,51,52,56,56,58$ and 11 others) as per the genotyping assay. Surprisingly, only $3 \%$ and $4 \%$ of the study population were infected soleley with HPV 16 and HPV 18 respectively (Fig. 1). 


\section{Factors associated with HPV-infection}

\section{Effect of age on HPV-infection}

The age range 20-29 years was the most infected by HPV (51.66\%). This latter prevalence was significantly higher when compared with that obtained in those aged $40-49$ years $(25.00 \%) ; p=0.03$. Overall, HPV positivity decreased as participants grow older (Table 2).

Table 2

HPV positivity by age

\begin{tabular}{|lllll|}
\hline $\begin{array}{l}\text { HPV } \\
\text { Age (years) }\end{array}$ & $\begin{array}{l}\text { HPV+ } \\
\mathbf{n}(\%)\end{array}$ & HPV- & Total & P-value \\
\hline $20-29$ & $31(51.66)$ & 29 & 60 & Ref \\
\hline $30-39$ & $49(41.52)$ & 69 & 118 & 0.20 \\
\hline $40-49$ & $16(25.00)$ & 48 & 64 & 0.03 \\
\hline $50-75$ & $11(30.55)$ & 25 & 36 & 0.64 \\
\hline Total & 107 & 171 & 278 & \\
\hline
\end{tabular}

Table 3

HPV Association and Marital Status

\begin{tabular}{|lllll|}
\hline $\begin{array}{l}\text { HPV } \\
\text { Marital status }\end{array}$ & $\begin{array}{l}\text { HPV } \\
\mathbf{n}(\%)\end{array}$ & HPV - & Total & P-value \\
\hline Single & $63(43.75)$ & 81 & 144 & Ref \\
\hline Married & $31(30.69)$ & 70 & 101 & 0.36 \\
\hline divorced & $3(60.00)$ & 2 & 5 & 0.04 \\
\hline Widow & $10(35.71)$ & 18 & 28 & 0.55 \\
\hline Total & 107 & 171 & 278 & 0.32 \\
\hline
\end{tabular}

Effect of marital status on HPV-infection

According to marital status, the highest HPV positivity rate was recorded among divorced women (60\%), and this latter prevalence was significantly higher when compard to those that were single $(p=0.04)$.

\section{Effect of immunity on HPV-infection}

Participants with poor immune status (CD $4 \leq 500)$ had a significantly higher rate of HPV positivity as compared to those with a normal immunity $(62.88 \%$ versus $35.71 \%$ respectively, $p=0.046)$. Interestingly, 
the lower the CD4-count, the higher the rate of HPV positivity (Table 4).

Table 4

HPV-infection according to immune status

\begin{tabular}{|lllll|}
\hline $\begin{array}{l}\text { HPV } \\
\left.\text { CD4 (cells } / \mathrm{mm}^{3}\right)\end{array}$ & HPV + & HPV - & Total & P-value \\
\hline $500-1600$ & $20(35.71 \%)$ & 36 & 56 & Ref \\
\hline $350-499$ & $26(55.31 \%)$ & 21 & 47 & 0.046 \\
\hline $200-350$ & $15(57.69 \%)$ & 11 & 26 & 0.844 \\
\hline$<200$ & $20(83.33 \%)$ & 4 & 24 & 0.048 \\
\hline Total & 81 & 72 & 153 & \\
\hline
\end{tabular}

\section{Effect of HIV viremia on HPV-infection}

Ovrall, HPV positivy seemingly increased with increasing values of viral loads. $42.71 \%(41 / 96)$ with < 1000 RNA copies/ml vs. $66.00 \%$ (33/50) with > 1000 RNA copies/ml $(O R=0.384 ; p=0.009)$. However, these increments were not statically significant (Table 5).

Table 5

HPV positivity rates by HIV viremia

\begin{tabular}{|lllll|}
\hline $\begin{array}{l}\text { HPV } \\
\text { Viremia (copies/mL) }\end{array}$ & $\begin{array}{l}\text { HPV+ } \\
\mathbf{n}(\%)\end{array}$ & HPV- & Total & P-value \\
\hline Undetectable & $25(39.68)$ & 38 & 63 & Ref \\
\hline $1.60-2.99 \log$ & $25(49.01)$ & 26 & 51 & 0.34 \\
\hline$>3 \log$ & $38(64.40)$ & 21 & 59 & 0.12 \\
\hline Total & 88 & 85 & 173 & \\
\hline
\end{tabular}

\section{Multi-variate analysis on HPV-infection}

After adjusting for CD4, viral load and HIV status, only HIV-infection was 12 times more likely to increase the risk of acquiring HPV-infection $(p=0.0001)$, as shown in Table 6. 
Table 6

Multi-variate analyses

\begin{tabular}{|lllcl|}
\hline Variable & Odds Ratio & \multicolumn{2}{l|}{ Confidence interval 95\% } & P-value \\
\hline CD4 : 500-1600 & 0.7323 & 0.2211 & 2.4260 & 0.6102 \\
\hline CD4 : 350-499 & 1.4735 & 0.4490 & 4.8361 & 0.5226 \\
\hline VL Undetectable & 0.3839 & 0.1273 & 1.1580 & 0.0892 \\
\hline VL 1.60-2.99 & 0.5316 & 0.1109 & 2.5487 & 0.4295 \\
\hline HIV status & 12.5000 & 4.0000 & 39.3000 & $<0.0001$ \\
\hline
\end{tabular}

\section{Discussion}

The purpose of our study was to compare the rate of HPV positivity among HIV-positive women with that of HIV-negative women, and to determine predictors of HPV-infection. Out of a sample of 278 women enrolled, the mean age (37 years) mainly represents the most sexually active population and therefore having chronic exposure to sexually transmitted infections, including HPV. These results are similar to those obtained in Chad (mean age of 35 years) [10].

According to marital status, single women were the most represented (58\%), a rate above the national proportion published in 2005 by the Central Bureau of Censuses and Population Studies in Cameroon where single women had a percentage of $41.46 \%$ [13]. the difference could be explained by changing overtime, as the social realities in the population could justify the increasing rate of single women [13].

The median CD4 count was lower in the frame of HIV-infection (354 versus 414 cells $/ \mathrm{mm}^{3}$ ] in HIVnegative women. Median CD4 obtained in HIV-free population was surprissing; howeever, this could be justified by the fact that these women attending the health facility (likely due to illed-health for some of them) [14-16]. Furthermore, a previous study had shown that CD4 cell levels can also vary in response to stress, smoking, the menstrual cycle, the contraceptive pill, recent physical activity or even the time of day [14].

The HR-HPV positivity rate was $38.48 \%$, with very low rate of vaccine genotypes (3\% for HPV monoinfection of genotype 16 and $4 \%$ for HPV mono-infection of genotype 18). This suggests that other genotypes are drivers of HPV-infection in the Cameroonian context and need to be depict among cervical cancer cases, especially in the frame of HIV-infection $[13,17]$. Our findings are comparable to those found in Central Africa Republic [18, 19], which suggest a predominance of non-vaccine HR-HPV different from those found in Western Europe and North America [20,21]. Thus, for better vaccination coverage, the use of Gardasil 9 in SSA may offers optimal protection $[9,10]$. Co-infections of several HR-HPV genotypes was also been recorded, similar to previous reports [22]. Multi-infections are often associated with viral persistence, especially if co-present with HPV 16. 
HIV is confirmed as a contributing factor to HPV-infection ( $p<0.019)$, also comfirmed by multi-variate analysis. As expected, women infected with HIV have a weaker immune status [23], which henceforth increases risk of acquiring HPV $[20,24]$. This calls for the need to regularly test people with HPV infection for HIV [20].

Younger age are at higher risk of acquiring HPV-infection, likely due to sexual habits [24]. Regarding marital status, divorced women stand at high risk of acquiring HR-HPV. The lack of statiscal power limits the interpretation of this finding. Nonetheless, divorced women might be prone to multiple sexual partners, leading to HPV-infection $[3,25,26]$. The lack of synergistic effect between the HIV viral load and HPV-infection simply comfirmed that HIV-infection interfers with HPV through immunodeficiency induced by HIV, and not via a direct viral-viral interaction [27-29].

After adjusting the different variables based on a multi-variate analysis, HIV status remains the independent factor associated with the risk of infection with this high-risk oncogenic HPV (12 times higher risk), as previously demonstrated $[29,31]$.

As study limitation, the reference molecular technique used for HPV detection made it possible to identify only vaccine genotypes 16 and 18 . Given the high rate of other genotypes, it becomes essential to characterize this group. This therefore calls for sequencing for a better molecular characterization toward a rational selection of HPV vaccine candidate for the country.

\section{Conclusion}

In this sub-population of Cameroonian women, HPV burden appears to be very high, with higher rates of genotypes other than the commonly known 16 and 18. Interestingly, in the event of HIV infection, the risk of HPV-infection bceomes higher, favoured essentially by immunodeficiency. The very high proportion of non-discriminative HPV genotypes calls for further studies to delineate the adequacy between the currenty unknown genotypes and vaccine candidates (gardasil-4, gardasil-9, or cervarix). This measure is highly urgent to prevent risk of cervical cancer among HIV-infected women.

\section{Abbreviations}

AIDS

Acquired immunodeficiency syndrome;

CD4

Cluster of differentiation 4;

CIRCB

"Chantal BIYA" International Reference Centre for research on HIV/AIDS prevention and management DNA

deoxyribonucleic acid

HIV 
Human Immunodeficiency Virus;

HPV

human papilloma virus

HR-HPV

high risk oncogenic Human Immunodeficiency Virus;

LR-HPV

low risk non-Human Immunodeficiency Virus;

PLHIV

People living with HIV;

RT-PCR

real-time polymerase chain reaction

WHO

world health organization

\section{Declarations}

\section{Ethics approval and consent to participate}

This study obtained ethical clearance from the CIRCB Ethics Committee on the Project $N^{0} 1810$ and also authorization from CIRCB where the study was conducted. The participants freely signed informed consent forms, which were written in French and English (with respect to the first language of the participant), while the minor participants provided their assent.

\section{Consent for publication:}

Not applicable.

\section{Disclosure statement}

Authors declare that they have no financial, personal, or professional interests that could be construed to have influenced this manuscript.

\section{Availability of data and materials}

The dataset is available from the corresponding author.

\section{Competing interests}

The authors declared that, this study is without conflicts of interests.

\section{Funding:}

The financial and material resources such as reagents, laboratory consumables and access to the various platforms for carrying out the biological analyzes of the samples was provides by CIRCB where 
analysis of samples and data has been heavily involved.

\section{Authors' contributions:}

All authors read and approved the final manuscript. SMS, MCTT, JF, RK, JT, AN, GN, and AN designed the study. MCTT, ADN, TV, CC, ENJS, AA, AK, and BY analysed and interpreted the data. SMS, JF, RK and MCTT performed the HPV testing. VC and AN managed all aspects of the study in Yaoundé. SMS and JF supervised the performance of laboratory testing. MCTT, JF, and SMS drafted the manuscript.

\section{Acknowledgements:}

Some of these data were selected for a poster presentation at the $13^{\text {th }}$ international Conference on HIV treatment pathogenesis (INTEREST 2019), Accra, Ghana (Reference number Poster 092).

The abstract of this work has been accepted for poster presentation at the 33rd International Papillomavirus Conference to be held in Barcelona, Spain.

We would like to thank the CIRCB for giving us the opportunity to initiate this first stage of this major project.

\section{Author details}

1. Chantal Biya International Reference Center for research on HIV/AIDS prevention and management (CIRCB), Yaoundé, Cameroon.

2. University of Yaoundé I, Cameroon

3. School of Health Sciences, Catholic University of Central Africa, Yaoundé, Cameroon

4. Yaoundé Gynaeco-obstetrics and paediatric hospital

5. University of Rome "Tor Vergata", Rome, Italy

6. Evangelical University of Bandjoun, Cameroon

\section{References}

1. Kjaer SK, Chackerian B, van den Brule AJ, Svare El, Paull G, Walbomers JM, et al. High-risk human papillomavirus is sexually transmitted: evidence from a follow-up study of virgins starting sexual activity (intercourse). Cancer Epidemiol Biomark Prev Publ Am Assoc Cancer Res Cosponsored Am Soc Prev Oncol. févr 2001;10(2):101-6.

2. Siracusano S, Silvestri T, Casotto D. Sexually transmitted diseases: epidemiological and clinical aspects in adults. Urologia. déc 2014;81(4):200-8.

3. de Sanjose S, Quint WG, Alemany L, Geraets DT, Klaustermeier JE, Lloveras B, et al. Human papillomavirus genotype attribution in invasive cervical cancer: a retrospective cross-sectional worldwide study. Lancet Oncol. nov 2010;11(11):1048-56. 
4. Bruni L, Diaz M, Castellsagué X, Ferrer E, Bosch FX, de Sanjosé S. Cervical human papillomavirus prevalence in 5 continents: meta-analysis of 1 million women with normal cytological findings. $J$ Infect Dis. 15 déc 2010;202(12):1789-99.

5. Ferlay J, Soerjomataram I, Dikshit R, Eser S, Mathers C, Rebelo M, et al. Cancer incidence and mortality worldwide: sources, methods and major patterns in GLOBOCAN 2012. Int J Cancer. 1 mars 2015;136(5):E359-386.

6. Organisation Mondiale de la Santé. Projections de la mortalité et des causes de décès, 2015 et 2030. 2015;

7. Amégbor K, Darre T, Ayéna KD, Padaro E, Tengué K, Abalo A, et al. Cancers in Togo from 1984 to 2008: Epidemiological and Pathological Aspects of 5251 Cases. J Cancer Epidemiol [Internet]. 2011 [cité 20 sept 2019];2011. Disponible sur: https://www.ncbi.nlm.nih.gov/pmc/articles/PMC3189592/

8. Parkin DM. The global health burden of infection-associated cancers in the year 2002. Int J Cancer. 15 juin 2006;118(12):3030-44.

9. Zhai L, Tumban E. Gardasil-9: A global survey of projected efficacy. Antiviral Res. 2016;130:101-9.

10. Mboumba Bouassa R-S, Nodjikouambaye ZA, Sadjoli D, Adawaye C, Péré H, Veyer D, et al. High prevalence of cervical high-risk human papillomavirus infection mostly covered by Gardasil-9 prophylactic vaccine in adult women living in N'Djamena, Chad. Fast PE, éditeur. PLOS ONE [Internet]. 3 juin 2019 [cité 20 sept 2019];14(6):e0217486. Disponible sur: http://dx.plos.org/10.1371/journal.pone.0217486

11. Mboumba Bouassa R-S, Prazuck T, Lethu T, Jenabian M-A, Meye J-F, Bélec L. Cervical cancer in subSaharan Africa: a preventable noncommunicable disease. Expert Rev Anti Infect Ther. 2017;15(6):613-27.

12. Lynge E, Rygaard C, Baillet MV-P, Dugué P-A, Sander BB, Bonde J, et al. Cervical cancer screening at crossroads. APMIS [Internet]. août 2014 [cité 20 sept 2019];122(8):667-73. Disponible sur: http://doi.wiley.com/10.1111/apm.12279

13. INS. comité national de lutte contre le cancer. Yaoundé Cameroun. 2016;

14. Etienne, L., \& Peeters, M. Origine du VIH, une réussite émergentielle. Virologie. 2010;171-84.

15. Massad LS, Xie X, D'Souza G, Darragh TM, Minkoff H, Wright R, et al. Incidence of cervical precancers among HIV-seropositive women. Am J Obstet Gynecol. mai 2015;212(5):606.e1-8.

16. Comité National de Lutte contre le SIDA. l'atteinte de l'objectif 90-90-90 d'ici l'horizon 2020. 2018;

17. Denslow SA, Rositch AF, Firnhaber C, Ting J, Smith JS. Incidence and progression of cervical lesions in women with HIV: a systematic global review. Int J STD AIDS. mars 2014;25(3):163-77.

18. pubmeddev, al A-RC et. [Human papillomavirus genotype profile in Kinshasa, Democratic Republic of the Congo: implications for vaccination]. - PubMed - NCBI [Internet]. [cité 22 sept 2019]. Disponible sur: https://www.ncbi.nlm.nih.gov/pubmed/19639831

19. Akom E, Venne S, Institut national de santé publique du Québec. L'infection au virus du papillome humain (VPH) recension des écrits et consultation d'experts dans une perspective de santé publique: 
ampleur et nature du problème, explorations des avenues de prévention de ces infections et de leurs complications [Internet]. Montréal: Institut national de santé publique; 2003 [cité 20 sept 2019]. Disponible sur: http://collections.banq.qc.ca/ark:/52327/50417

20. pubmeddev, al CG et. Worldwide distribution of human papillomavirus types in cytologically normal women in the International Agency for Research on Cancer HPV prevalenc... - PubMed - NCBI [Internet]. [cité 22 sept 2019]. Disponible sur: https://www.ncbi.nlm.nih.gov/pubmed/16168781

21. Muñoz N, Bosch FX, Castellsagué X, Díaz M, de Sanjose S, Hammouda D, et al. Against which human papillomavirus types shall we vaccinate and screen? The international perspective. Int $\mathrm{J}$ Cancer. 20 août 2004;111(2):278-85.

22. Perrons C, Jelley R, Kleter B, Quint W, Brink N. Detection of persistent high risk human papillomavirus infections with hybrid capture II and SPF10/LiPA. J Clin Virol Off Publ Pan Am Soc Clin Virol. avr 2005;32(4):278-85.

23. Massad LS, Silverberg MJ, Springer G, Minkoff H, Hessol N, Palefsky JM, et al. Effect of antiretroviral therapy on the incidence of genital warts and vulvar neoplasia among women with the human immunodeficiency virus. Am J Obstet Gynecol. mai 2004;190(5):1241-8.

24. Muñoz N, Castellsagué X, de González AB, Gissmann L. Chapter 1: HPV in the etiology of human cancer. Vaccine. 31 août 2006;24 Suppl 3:S3/1-10.

25. Kahn JA, Rudy BJ, Xu J, Kapogiannis B. Prevalence and risk factors for oral DNA tumor viruses in HIV-infected youth. J Med Virol. 1 nov 2016;88(11):1944.

26. Badial RM, Dias MC, Stuqui B, Melli PPDS. Detection and genotyping of human papillomavirus (HPV) in HIV-infected women and its relationship with HPV/HIV co-infection. Medicine (Baltimore). $1 \mathrm{avr}$ 2018;97(14):e9545.

27. Castellsagué $X$, Paavonen J, Jaisamrarn U, Wheeler CM, Skinner SR, Lehtinen M, et al. Risk of first cervical HPV infection and pre-cancerous lesions after onset of sexual activity: analysis of women in the control arm of the randomized, controlled PATRICIA trial. BMC Infect Dis. 30 oct 2014;14:551.

28. Tian T, Mijiti P, Bingxue H, Fadong Z. Prevalence and risk factors of anal human papillomavirus infection among HIV-negative men who have sex with men in Urumqi city of Xinjiang Uyghur Autonomous Region, China. PLoS ONE. 12(11):e0187928.

29. van der Burg SH, Palefsky JM. Human immunodeficiency virus and human papilloma virus - why HPV-induced lesions do not spontaneously resolve and why therapeutic vaccination can be successful. J Transl Med [Internet]. 18 déc 2009 [cité 20 sept 2019];7:108. Disponible sur: https://www.ncbi.nlm.nih.gov/pmc/articles/PMC2802355/

30. Moscicki A-B. Risks for Incident Human Papillomavirus Infection and Low-Grade Squamous Intraepithelial Lesion Development in Young Females. JAMA [Internet]. 20 juin 2001 [cité 20 sept 2019];285(23):2995. Disponible sur: http://jama.jamanetwork.com/article.aspx? doi=10.1001/jama.285.23.2995

31. Piketty C, Darragh TM, Da Costa M, Bruneval P, Heard I, Kazatchkine MD, et al. High prevalence of anal human papillomavirus infection and anal cancer precursors among HIV-infected persons in the 
absence of anal intercourse. Ann Intern Med. 18 mars 2003;138(6):453-9.

32. Williamson A-L. The Interaction between Human Immunodeficiency Virus and Human Papillomaviruses in Heterosexuals in Africa. J Clin Med. 2 avr 2015;4(4):579-92.

\section{Figures}

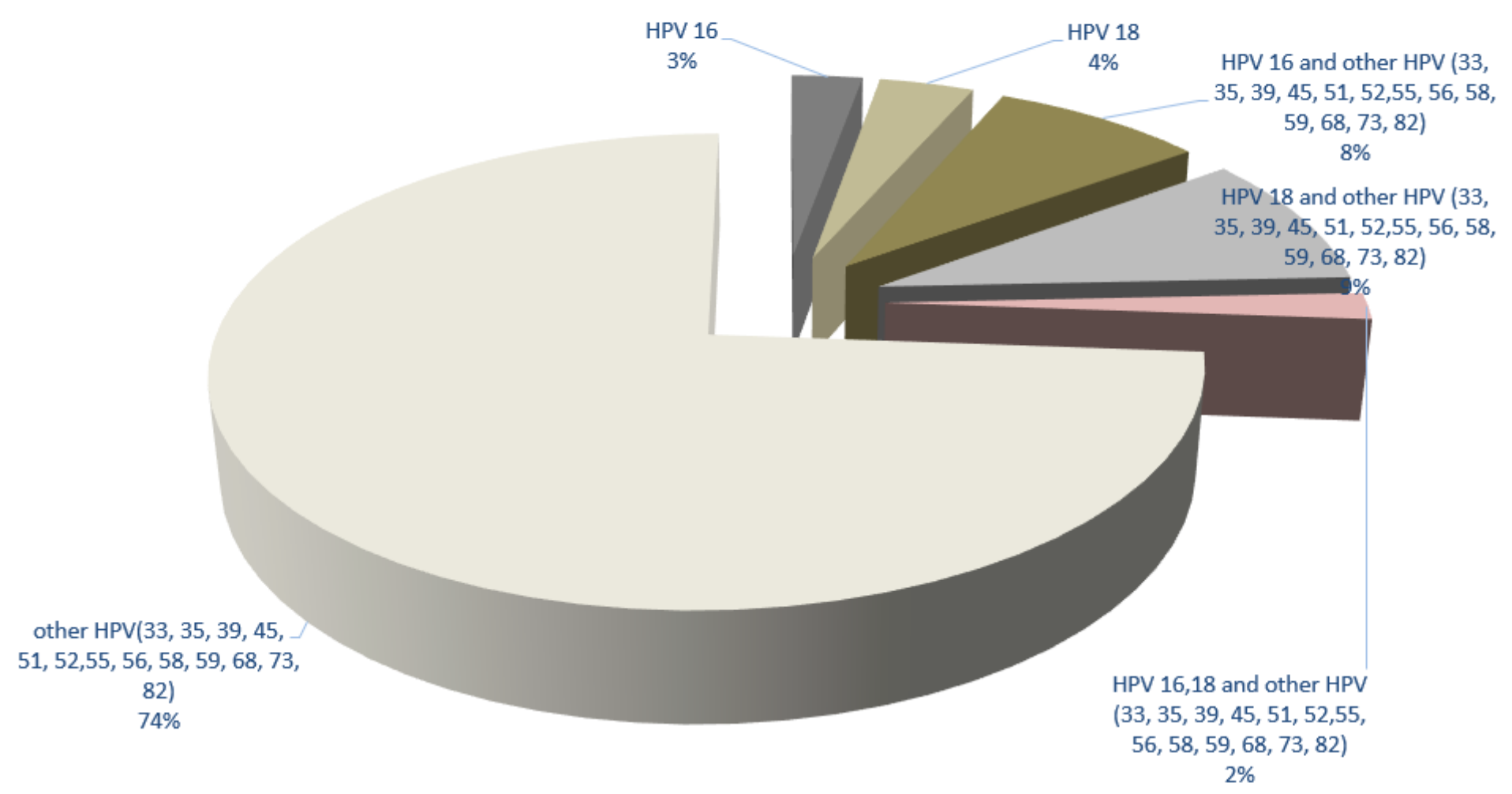

Figure 1

Distribution of HPV genotypes. HPV: human papillomavirus; others refer to oncogenic HPV other than the 16 and 18 genotypes identified by the molecular detection assay. 